\title{
Cross-validation of generalised body composition equations with diverse young men and women: the Training Intervention and Genetics of Exercise Response (TIGER) Study
}

\author{
Andrew S. Jackson ${ }^{1}$, Kenneth J. Ellis ${ }^{2}$, Brian K. McFarlin ${ }^{1}$, Mary H. Sailors ${ }^{2}$ and Molly S. Bray ${ }^{2}$ \\ ${ }^{1}$ University of Houston, Department of Health and Human Performance, 3855 Holman Street, Houston, TX 77204-6015, USA \\ ${ }^{2}$ USDA/ARS Children's Nutrition Research Center, Baylor College of Medicine, Houston, TX, USA \\ (Received 9 January 2008 - Revised 24 June 2008 - Accepted 26 June 2008 - First published online 15 August 2008)
}

Generalised skinfold equations developed in the 1970s are commonly used to estimate laboratory-measured percentage fat (BF\%). The equations were developed on predominately white individuals using Siri's two-component percentage fat equation (BF\%-GEN). We cross-validated the Jackson-Pollock (JP) generalised equations with samples of young white, Hispanic and African-American men and women using dual-energy X-ray absorptiometry (DXA) as the BF\% referent criterion (BF\%-DXA). The cross-sectional sample included 1129 women and men (aged 17-35 years). The correlations between BF\%-GEN and BF\%-DXA were 0.85 for women and 0.93 for men. Analysis of measurement error showed that BF\%-GEN underestimated BF\%-DXA of men and women by 1.3 and $3.0 \%$. General linear models (GLM) confirmed that BF\%-GEN systematically underestimated BF\%-DXA of Hispanic men and women, and overestimated BF\%-DXA of African-American men. GLM were used to estimate BF\%-DXA from the JP sum of skinfolds and to account for race/ethnic group bias. The fit statistics $(R$ and standard error of the estimate; SEE) of the men's calibration model were: white, $R 0.92$, SEE $3.0 \%$; Hispanic, $R$ 0.91, SEE 3.0\%; African-American, $R 0.95$, SEE $2.6 \%$. The women's statistics were: white and African-American, $R 0.86$, sEE $3.8 \%$; Hispanic, $R 0.83$, sEE $3.4 \%$. These results showed that BF\%-GEN and BF\%-DXA were highly correlated, but the error analyses documented that the generalised equations lacked accuracy when applied to these racially and ethnically diverse men and women. The inaccuracy was linked to the body composition and race/ethnic differences between these Training Intervention and Genetics of Exercise Response (TIGER) study subjects and the men and women used to develop the generalised equations in the 1970s and using BF\%-DXA as the referent criterion.

Body composition: Skinfolds: Dual-energy X-ray absorptiometry: Generalised equations

Anthropometric variables are often used to estimate laboratory-measured body composition ${ }^{(1)}$. This validation methodology involves using cross-sectional data and multiple regression to develop valid prediction equations to estimate a referent percentage fat (body fat percentage; $\mathrm{BF} \%$ ) criterion $^{(2)}$. The initial research approach was to develop population-specific equations using relatively homogeneous samples, such as young and middle-aged men and women $^{(3-8)}$. In the $1970 \mathrm{~s}$, researchers ${ }^{(9-11)}$ published what have been termed 'generalised body composition equations'. The generalised equations used large, variable samples of men and women and modelled the data to account for age and the non-linear relationship between body density and skinfold fat. The Jackson-Pollock (JP) generalised equation validation research ${ }^{(10,11)}$ has been cited over 1300 times in the scientific literature and the men's study was reproduced in 2004 as a British Journal of Nutrition citation classic $^{(12)}$.
The original JP generalised equations ${ }^{(10,11)}$ were published with data obtained in the 1970s. The American population has become more racially and ethnically diverse and, during this time, the prevalence of obesity in the American population has increased ${ }^{(13)}$. Race/ethnic diversity has been shown to be associated with body composition variation ${ }^{(14)}$. The subjects used to develop the original JP generalised equations were predominately white men and women and the body composition reference criterion was hydrodensitometry-determined body density ${ }^{(15)}$ converted to $\mathrm{BF} \%$ with the Siri two-component (2-C) model $^{(16)}$. Multicomponent models $^{(17-19)}$ have replaced the $2-\mathrm{C}$ model as the reference criterion. The changes in body composition and race/ethnic composition of the American population and the adoption of multicomponent body composition reference criteria raise questions concerning the validity and accuracy of the JP generalised equations when used with contemporary men and women. Our purpose was to cross-validate the generalised

\footnotetext{
Abbreviations: BF\%, body fat percentage; BF\%-Diff, difference between BF\% from dual-energy X-ray absorptiometry and BF\% from Siri's two-component percentage fat equation; BF\%-DXA, body fat percentage from dual-energy X-ray absorptiometry; BF\%-GEN, body fat percentage from Siri's two-component percentage fat equation; 2-C, two-component; DXA, dual-energy X-ray absorptiometry; GLM, general linear model; JP, Jackson-Pollock; NHANES, National Health and Nutrition Examination Survey; SEE, standard error of the estimate; TIGER, Training Intervention and Genetics of Exercise Response.

* Corresponding author: Dr Andrew S. Jackson, fax +1 713743 9860, email udde@mac.com
} 
equations on samples of non-Hispanic white, Hispanic and African-American men and women using dual-energy $\mathrm{X}$-ray absorptiometry (DXA) as the $\mathrm{BF} \%$ referent criterion (BF\%-DXA).

\section{Methods \\ Samples}

Subjects were drawn from the 5-year Training Intervention and Genetics of Exercise Response (TIGER) study. The diverse sample consisted of 706 women and 423 men who ranged in age from 17 to 35 years. The race/ethnic breakdown of the total sample was: non-Hispanic white (white), $37.1 \%$; Hispanic white (Hispanic), 28.8\%; African-American, $34.1 \%$. The TIGER subjects were students enrolled at the University of Houston (Houston, TX, USA) who agreed to participate in the TIGER study. The published JP descriptive data used to develop the original generalised equations were compared with the TIGER subjects. The JP men and women came from two general sources: students, faculty and staff at Wake Forest University (Winston-Salem, NC, USA) and patients and research volunteers at the Cooper Institute (Dallas, TX, USA). The racial/ethnic composition of these men and women was not reported, but nearly all were white. All TIGER subjects completed a written informed consent before being measured. All procedures were approved by the protection of human subjects committees at the University of Houston and Baylor College of Medicine.

\section{Measurement methods}

The cross-sectional TIGER data were obtained from the baseline visit. Height was determined with a stadiometer (Seca Road Rod; Seca Corp., Hanover, MD, USA) and weight was measured with a digital scale (Seca 770). Each subject reported birth date, sex, and race/ethnicity using a coded self-report demographic form. Whole-body DXA scans were completed on two Hologic units (Hologic, Bedford, MA, USA). The data for the year 2003 were obtained on a Hologic Delphia-A unit (adult whole body software v. 11.2) at the body composition laboratory at the US Department of Agriculture/ Agricultural Research Service (USDA/ARS) Children's Nutrition Research Center (Baylor College of Medicine, Houston, TX, USA). The DXA scans for the final 4 years were obtained on a Hologic Discovery $\mathrm{W}$ instrument (adult whole body software QDR version 12.3; Hologic) housed in the Obesity Research Center in the Health and Human Performance Department (University of Houston, Houston, TX, USA). The same trained technicians administered all DXA scans. The instruments were calibrated daily with a spine criterion and weekly with a step calibrator, as described by the manufacturer. All female participants completed a criterion urine pregnancy test before DXA testing to ensure that they were not pregnant. Subjects were asked to lie in the supine position, remain still, and the entire scan was completed in less than 6 min. Whole-body (minus the head) fat mass, lean mass, bone mass and $\mathrm{BF} \%$ were determined using the software supplied by the manufacturer. Following the recommendation of Lohman \& Chen ${ }^{(18)}$, DXA-measured body mass was compared with body mass measured with the digital scale.
The correlation between scale-measured and DXA-determined body mass was 0.997 (standard error of the estimate (SEE) $1.6 \mathrm{~kg})$.

The JP sum of three-skinfold generalised equations ${ }^{(10,11)}$ was applied to the TIGER data to estimate BF\% from Siri's two-component percentage fat equation (BF\%-GEN). The male skinfold sites were chest, abdomen and thigh. The three female sites were triceps, supra-ilium and thigh. The TIGER skinfold measurement methods replicated those used in the original work ${ }^{(20,21)}$. The generalised equations have functions to estimate body density from the quadratic form of the sum of the three skinfolds in combination with age. Estimated body density was converted to $\mathrm{BF} \%$ using the Siri $2-\mathrm{C}$ model ${ }^{(16)}$. The published validity correlations and SEE expressed in the metric of body density and Siri 2-C BF\% are: men, $R 0.905$ (SEE $0.008 \mathrm{~kg} / \mathrm{l}, 3.40 \%$ ); women, $R \quad 0.842$ (SEE $0.008 \mathrm{~kg} / \mathrm{l}$, $3.92 \%)^{(10,11)}$.

\section{Statistical methods}

STATA software (version 10; StataCorp LP, College Station, TX, USA) ${ }^{(22)}$ was used for all statistical analyses. ANOVA evaluated the mean differences between the JP and TIGER samples, and among the three ethnic/race groups. The crossvalidation of the generalised equations on the TIGER men and women involved several steps. First, product-moment correlations examined the relationship between BF\%-GEN and BF\%-DXA. General linear models (GLM) defined the relationship between $\mathrm{BF} \%-\mathrm{GEN}$ and $\mathrm{BF} \%$-DXA and examined the effect of sex. The method outlined by Pedhauzur ${ }^{(23)}$ was used to test for homogeneity of the male and female regression slopes and intercepts. The accuracy of the BF\%-GEN was examined graphically by the Bland-Altman method $^{(24,25)}$. GLM determined if race/ethnic group accounted for $\mathrm{BF} \%$-DXA variance independent of $\mathrm{BF} \%-\mathrm{GEN}$, and if race/ethnic group interacted with $\mathrm{BF} \%-\mathrm{GEN}$.

\section{Results}

Table 1 gives the descriptive statistics of the men and women for both samples. ANOVA confirmed that TIGER men and women differed $(P<0.001)$ from the JP subjects on all variables. The male and female trends were similar. The TIGER men and women were younger, shorter and heavier. The TIGER women and men were 2.5 and $3.0 \mathrm{~cm}$ shorter than the JP men and women. The TIGER men were $6.75 \mathrm{~kg}$ heavier than the JP men, and the weight difference for women was nearly $13 \mathrm{~kg}$. These height and weight differences produced significant BMI differences. The mean BMI differences were: men, $2 \cdot 82 \mathrm{~kg} / \mathrm{m}^{2}$; women, $5 \cdot 36 \mathrm{~kg} / \mathrm{m}^{2}$. The proportion of men and women who exceeded the BMI overweight criterion of $\geqq 25 \mathrm{~kg} / \mathrm{m}^{2}$ was higher for the TIGER subjects. Nearly $62 \%$ of the TIGER men were overweight compared with $42 \%$ of the JP men. Just $6 \%$ of the JP women had a BMI $\geqq 25 \mathrm{~kg} / \mathrm{m}^{2}$ compared with nearly $46 \%$ for the TIGER women. The mean differences for the sum of three skinfolds for the TIGER and JP men and women were about $10 \mathrm{~mm}$ and $20 \mathrm{~mm}$, respectively. These skinfold fat differences produced BF\%-GEN differences of $0.9 \%$ for men and nearly $8 \%$ for females. Table 1 gives the BF\%-DXA descriptive statistics for the TIGER samples and the difference between 
Table 1. Characteristics of Jackson-Pollock and Training Intervention and Genetics of Exercise Response (TIGER) study

(Mean values and standard deviations)

\begin{tabular}{|c|c|c|c|c|}
\hline & \multicolumn{2}{|c|}{ Males } & \multicolumn{2}{|c|}{ Females } \\
\hline & Mean & SD & Mean & SD \\
\hline \multicolumn{5}{|l|}{ Jackson-Pollock samples } \\
\hline Subjects $(n)$ & \multicolumn{2}{|c|}{400} & \multicolumn{2}{|c|}{279} \\
\hline Age (years) & $32 \cdot 77$ & 11.00 & 31.62 & 11.46 \\
\hline Height $(\mathrm{cm})$ & 179.03 & 6.36 & $165 \cdot 37$ & 5.66 \\
\hline Weight (kg) & 78.02 & 11.61 & 57.50 & 7.38 \\
\hline $\operatorname{BMI}\left(\mathrm{kg} / \mathrm{m}^{2}\right)$ & 24.49 & 3.35 & 21.05 & 2.34 \\
\hline Sum of skinfolds (mm) & 59.18 & 24.51 & $61 \cdot 61$ & $19 \cdot 10$ \\
\hline BF\%-GEN (\%) & 17.97 & 8.0 & $24 \cdot 37$ & $7 \cdot 24$ \\
\hline \multicolumn{5}{|l|}{ TIGER samples } \\
\hline Subjects $(n)$ & \multicolumn{2}{|c|}{423} & \multicolumn{2}{|c|}{706} \\
\hline Age (years) & 21.68 & 3.02 & $21 \cdot 19$ & 3.06 \\
\hline Height $(\mathrm{cm})$ & 176.02 & 6.69 & $162 \cdot 85$ & $6 \cdot 66$ \\
\hline Weight (kg) & 84.77 & 19.35 & $70 \cdot 11$ & 17.94 \\
\hline $\mathrm{BMI}\left(\mathrm{kg} / \mathrm{m}^{2}\right)$ & $27 \cdot 31$ & 5.66 & $26 \cdot 41$ & $6 \cdot 32$ \\
\hline Sum of skinfolds (mm) & 69.41 & $38 \cdot 36$ & 81.44 & 28.59 \\
\hline BF\%-GEN (\%) & 18.90 & 9.47 & 29.22 & 7.37 \\
\hline BF\%-DXA (\%) & $20 \cdot 22$ & 7.99 & $32 \cdot 21$ & 7.56 \\
\hline BF\%-Diff (\%) & 1.32 & 3.61 & 2.99 & 4.06 \\
\hline
\end{tabular}

BF\%-DXA and BF\%-GEN (BF\%-Diff). The BF\%-DXA of the TIGER subjects was higher than BF\%-GEN. The mean $\mathrm{BF} \%$-Diff was $1.32 \%\left(t_{(422)}=7.51 ; P<0.001\right)$ for men and $2.99 \%\left(t_{(705)}=19.55 ; P<0.001\right)$ for women.
Table 2 gives the descriptive statistics for the TIGER men and women contrasted by race/ethnic group. The Table includes the group sample sizes and the means and standard deviations. ANOVA with Bonferroni contrasts ${ }^{(22)}$ confirmed that white and African-American men and women were taller than Hispanic men and women $(P<0 \cdot 001)$. The mean weight of the African-American women was significantly higher than white and Hispanic women $(P<0.001)$. The BMI of white women was significantly lower than AfricanAmerican women $(P=0.003)$, but within chance variation of Hispanic women $(P=0 \cdot 152)$. The mean weight $(P=0.572)$ and BMI $(P=0.528)$ of the male race/ethnic groups was not significantly different. The women's race/ethnic group differences were within chance variation for the sum of skinfold fat $(P=0.281)$ and $\mathrm{BF} \%-\mathrm{GEN}(P=0.335)$, but the mean BF\%-DXA of Hispanic women was significantly $(P<0.001)$ higher than white and African-American women. The sum of skinfolds, BF\%-GEN and BF\%-DXA means of the African-American men were significantly $(P<0.01)$ lower than the means of white and Hispanic men. The BF\%-GEN and BF\%-DXA means of white and Hispanic men were not significantly different.

Fig. 1 gives the BF\%-DXA and BF\%-GEN bivariate plots of the TIGER men and women's data. Provided are the male and female regression lines (line of best fit) and, for reference, the line of identity (slope $=1 \cdot 0$, intercept $=0$ ). The correlation between BF\%-DXA and BF\%-GEN for the males and females combined was 0.91 . When contrasted separately, the correlations were 0.85 for women and 0.93 for men. GLM were used to test for differences between the slopes and intercepts of the BF\%-DXA and BF\%-GEN male

Table 2. Characteristics of the Training Intervention and Genetics of Exercise Response (TIGER) men and women contrasted by race/ethnic groups

(Mean values and standard deviations)

\begin{tabular}{|c|c|c|c|c|c|c|}
\hline & \multicolumn{2}{|c|}{ White } & \multicolumn{2}{|c|}{ Hispanic } & \multicolumn{2}{|c|}{ African-American } \\
\hline & Mean & SD & Mean & SD & Mean & SD \\
\hline \multicolumn{7}{|l|}{ TIGER females } \\
\hline Subjects $(n)$ & \multirow{2}{*}{\multicolumn{2}{|c|}{$\begin{array}{l}233 \\
33.0\end{array}$}} & \multirow{2}{*}{\multicolumn{2}{|c|}{$\begin{array}{c}196 \\
27 \cdot 8\end{array}$}} & \multicolumn{2}{|c|}{277} \\
\hline Subjects (\%) & & & & & \multicolumn{2}{|c|}{39.2} \\
\hline Age (years) & $21 \cdot 29$ & 2.89 & 21.32 & $2 \cdot 89$ & 21.03 & 3.31 \\
\hline Height $(\mathrm{cm})$ & 164.69 & $6 \cdot 61$ & $159 \cdot 43$ & $5 \cdot 68$ & 163.74 & 6.46 \\
\hline Weight (kg) & 68.73 & $16 \cdot 86$ & 67.47 & $15 \cdot 84$ & 3.13 & $19 \cdot 75$ \\
\hline $\mathrm{BMI}\left(\mathrm{kg} / \mathrm{m}^{2}\right)$ & $25 \cdot 35$ & 5.93 & $26 \cdot 54$ & 5.95 & $27 \cdot 20$ & $6 \cdot 77$ \\
\hline Sum of skinfolds $(\mathrm{mm})$ & 79.02 & 25.98 & 82.97 & $26 \cdot 96$ & 82.40 & 31.62 \\
\hline BF\%-GEN & $28 \cdot 70$ & $6 \cdot 817$ & $29 \cdot 74$ & $6 \cdot 80$ & $29 \cdot 29$ & $8 \cdot 15$ \\
\hline BF\%-DXA & 31.27 & $7 \cdot 35$ & 34.40 & $6 \cdot 69$ & 31.44 & 8.05 \\
\hline BF\%-Diff & 2.58 & 4.02 & 4.66 & 3.60 & $2 \cdot 14$ & 4.07 \\
\hline \multicolumn{7}{|l|}{ TIGER males } \\
\hline Subjects $(n)$ & \multirow{2}{*}{\multicolumn{2}{|c|}{$\begin{array}{r}186 \\
44.0\end{array}$}} & \multirow{2}{*}{\multicolumn{2}{|c|}{$\begin{array}{r}129 \\
30.5\end{array}$}} & \multirow{2}{*}{\multicolumn{2}{|c|}{$\begin{array}{c}108 \\
25.5\end{array}$}} \\
\hline Subjects (\%) & & & & & & \\
\hline Age (years) & $22 \cdot 16$ & $3 \cdot 30$ & 21.58 & $2 \cdot 62$ & 20.95 & $2 \cdot 83$ \\
\hline Height $(\mathrm{cm})$ & $177 \cdot 26$ & 6.08 & 173.05 & 6.49 & 177.43 & 6.84 \\
\hline Weight (kg) & 85.01 & $18 \cdot 07$ & 83.39 & 19.95 & 86.00 & $20 \cdot 80$ \\
\hline $\operatorname{BMI}\left(\mathrm{kg} / \mathrm{m}^{2}\right)$ & 27.03 & $5 \cdot 34$ & $27 \cdot 76$ & $5 \cdot 79$ & $27 \cdot 26$ & 6.042 \\
\hline Sum of skinfolds $(\mathrm{mm})$ & $73 \cdot 19$ & $36 \cdot 64$ & 73.82 & 35.80 & $57 \cdot 62$ & 41.96 \\
\hline BF\%-GEN & $20 \cdot 02$ & $9 \cdot 01$ & $20 \cdot 16$ & 8.74 & 15.46 & $10 \cdot 31$ \\
\hline BF\%-DXA & 21.07 & $7 \cdot 66$ & 21.90 & $7 \cdot 17$ & $16 \cdot 73$ & 8.49 \\
\hline BF\%-Diff & 1.05 & 3.67 & 1.74 & $3 \cdot 70$ & $1 \cdot 27$ & 3.37 \\
\hline
\end{tabular}

BF\%-GEN, body fat percentage from Siri's two-component percentage fat equation; BF\%-DXA, body fat percentage from dual-energy X-ray absorptiometry; BF\%-Diff, difference between BF\% from dual-energy X-ray absorptiometry and BF\% from Siri's two-component percentage fat equation. 


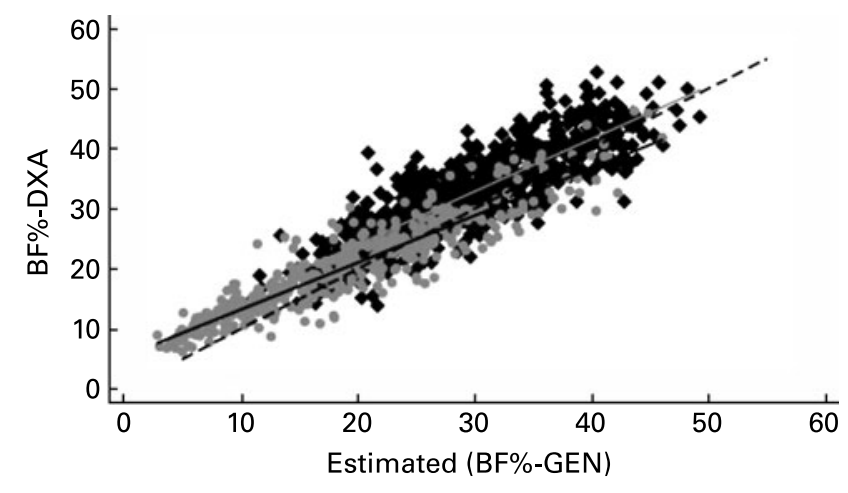

Fig. 1. Bivariate relationship between male $(\odot)$ and female $(\diamond)$ body fat percentage from dual-energy $\mathrm{X}$-ray absorptiometry (BF\%-DXA) and body fat percentage from Siri's two-component percentage fat equation (BF\%-GEN). -- , Line of identity (slope $=1$, intercept $=0$ ); - , linear line of best fit for women; - linear line of best fit for men.

and female regression lines. This analysis showed that the male and female slopes $(0.78 v .0 \cdot 88)$ were significantly different $\left(F_{(1,1125)}=125 \cdot 62 ; P<0 \cdot 001\right)$. The women's line of best fit (grey line) was significantly steeper than the male line (black line). Fig. 2 gives the male and female BlandAltman plots ${ }^{(24,25)}$ of the BF\%-DXA and BF\%-GEN differences and averages. For reference, the male and female regression lines are provided and a dashed line for a mean difference of 0 . The slope $(b=0.03)$ of the female line (grey line) was not significantly different from $0(P=0 \cdot 160)$, but the male slope of $-0 \cdot 17$ (black line) was $P<0 \cdot 001$. The data in Fig. 2 documented that BF\%-GEN underestimated $\mathrm{BF} \%$-DXA over all levels of the women's average of BF\%DXA and BF\%-GEN. The men's generalised equation underestimated $\mathrm{BF} \%$-DXA at the lower levels of the average of BF\%-DXA and BF\%-GEN, which was below about $27 \%$. The $95 \%$ limits of agreement were $-5 \cdot 14$ to $11.1 \%$ for women and -5.58 to $8.51 \%$ for men.

Table 2 gives the BF\%-Diff means and standard deviations contrasted by race/ethnic group and sex. The BF\%-Diff for Hispanic and African-American men and women were

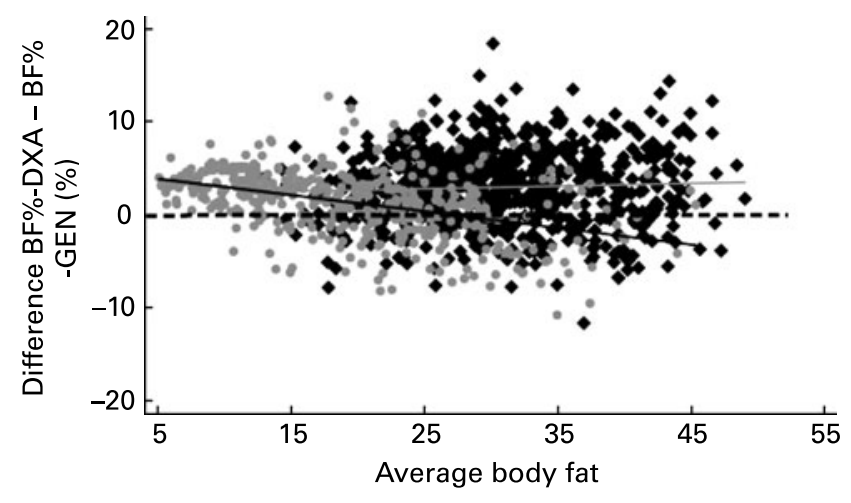

Fig. 2. Bland-Altman plots of the measurement error for the Training Intervention and Genetics of Exercise Response (TIGER) men ( $)$ and women $(\diamond)$. --, Measurement error of 0 ; - , regression line for the body fat percentage from dual-energy X-ray absorptiometry (BF\%-DXA) and body fat percentage from Siri's two-component percentage fat equation (BF\%-GEN) mean and difference for the women; - , regression line for the BF\%-DXA and BF\%-GEN mean and difference for men. The $95 \%$ limits of agreement were: males, -5.31 to 7.92 ; females, -4.56 to $11.44 \mathrm{BF} \%$. larger than for white men and women, suggesting that race/ ethnic group was a source of prediction bias. The GLM was used to determine if race/ethnic group accounted for BF\%-DXA variance independent of BF\%-GEN. Table 3 gives these analyses. Provided are two GLM models for men and women: GLM I includes just BF\%-GEN; GLM II adds race/ethnic group to the model. Race/ethnic group was entered into the GLM as a categorical variable using white men and women as the referent groups (regression coefficient $=0$ ). Race/ethnic group accounted for $0.64 \%$ of additional BF\%-DXA variance beyond BF\%-GEN for men and $2.73 \%$ for women. These increases were statistically significant for both men $\left(F_{(4,419)}=15.85 ; P<0.001\right)$ and women $\left(F_{(4,702)}=57.66 ; \quad P<0 \cdot 001\right)$. Post hoc analysis showed that, for the same BF\%-GEN, the BF\%-DXA of African-American men was overestimated by $0.81 \%$ and underestimated BF\%-DXA of Hispanic men by $0.73 \%$. These effects were small, but statistically significant $(P<0.03)$. The regression weight $(\mathrm{b}=2 \cdot 22)$ for Hispanic women was significantly $(P<0.001)$ different from zero, but the African-American regression weight of -0.35 was within chance variation $(P=0.303)$ of white women. The test for the $\mathrm{BF} \%$-GEN $\times$ race/ethnic group interaction of males $\left(F_{(2,417)}=0.51 ; \quad P=0.600\right)$ and females $\left(F_{(2,700)}=0.78 ; P=0.460\right)$ was not statistically significant.

The Bland-Altman (Fig. 2) and GLM analysis (Table 3) documented that the methods were highly correlated, but the generalised equations did not accurately estimate BF\%DXA. The GLM was used to derive calibration equations to estimate BF\%-DXA from the JP sum of three skinfolds. Table 4 gives these calibration models for men and women. The JP equations in the Siri 2-C BF\% metric are provided for reference. Like the original JP analyses that used Siri 2-C BF\% as the dependent variable, these analyses showed that the relationship between $\mathrm{BF} \%$-DXA and skinfold fat was quadratic $(P<0 \cdot 001)$. Table 4 shows that the linear and quadratic regression weights for the calibrated models are similar to the JP regression weights. Unlike the original JP analyses, age was not statistically significant for either men $(P=0.834)$ or women $(P=0.423)$. Provided in Table 4 are race/ethnic group-specific equations. The race/ethnic group bias was accounted for by summing the intercepts of white men and women with the significant race/ethnic group regression coefficient. The calibration model fit statistics $(R$, SEE) were slightly better than the original published JP statistics ${ }^{(10,11)}$. The male and female residual distributions were graphically examined with histograms and standardised normal probability plots ${ }^{(22)}$. The graphic plots (data not presented) showed there were no observed deviations from a normal distribution.

\section{Discussion}

These results showed that BF\%-GEN and BF\%-DXA were highly correlated. The male and female correlations in Table 3 were consistent with the validity correlations of 0.905 and 0.842 reported in the JP original research ${ }^{(10,11)}$. A correlation is a measure of association and not accuracy between the two measures. Equation accuracy involves analysing measurement error and determining the level of agreement between the two measures ${ }^{(24,25)}$. The limits of agreement analyses showed that 
Table 3. General linear model (GLM) analysis of body fat percentage from Siri's two-component percentage fat equation (BF\%-GEN) and race/ethnic group using white men and women as the referent group

(Regression coefficients and standard errors)

\begin{tabular}{|c|c|c|c|c|c|c|c|c|}
\hline \multirow{3}{*}{ Regression models... } & \multicolumn{4}{|c|}{ Men's models } & \multicolumn{4}{|c|}{ Women's models } \\
\hline & \multicolumn{2}{|c|}{ GLM I } & \multicolumn{2}{|c|}{ GLM II } & \multicolumn{2}{|c|}{ GLM I } & \multicolumn{2}{|c|}{ GLM II } \\
\hline & Estimate & SE & Estimate & SE & Estimate & SE & Estimate & SE \\
\hline Constant & $5 \cdot 41^{*}$ & 0.32 & $5 \cdot 61^{*}$ & 0.37 & $6 \cdot 59^{\star}$ & 0.61 & $6 \cdot 28^{*}$ & 0.61 \\
\hline BF\%-GEN & $0.78^{*}$ & 0.02 & $0.77^{\star}$ & 0.02 & $0.88^{\star}$ & 0.02 & $0.87^{*}$ & 0.02 \\
\hline Hispanic & & & $0.73^{\star \star}$ & 0.36 & & & $2 \cdot 22^{*}$ & 0.37 \\
\hline African-American & & & $-0.81^{\star *}$ & 0.38 & & & -0.35 & 0.34 \\
\hline \multicolumn{9}{|l|}{ Model statistics } \\
\hline$R$ & $0.93^{*}$ & & 0.93 & & 0.85 & & $0.87^{*}$ & \\
\hline$R^{2} \times 100$ & $86 \cdot 23^{*}$ & & $86 \cdot 87^{\star}$ & & $72 \cdot 72^{*}$ & & $75 \cdot 45^{\star}$ & \\
\hline$\Delta R^{2} \times 100$ & - & & $0.64^{* *}$ & & - & & $2 \cdot 73$ & \\
\hline SE of the estimate & 2.97 & & 2.92 & & 3.96 & & $3 \cdot 81$ & \\
\hline
\end{tabular}

${ }^{\star} P<0.01,{ }^{* \star} P<0.03$.

the generalised equations gave biased $\mathrm{BF} \%$-DXA estimates when applied to these samples of diverse men and women.

Figs. 1 and 2 show that sex was a source of measurement bias. This suggests that the cohort differences may be a source of the sex bias. The data in Table 1 compared the body composition differences between the TIGER and JP men and women. Both BMI and skinfold fat of the TIGER men and women were significantly, and substantially higher, than the JP subjects. A comparison of BMI means of the JP men with Second National Health and Nutrition Examination Survey (NHANES II) 1976-80 data ${ }^{(13)}$ showed that the body composition of the JP and NHANES II men was similar. The mean BMI of the NHANES II men was $24 \cdot 3 \mathrm{~kg} / \mathrm{m}^{2}$ for the 20-29 years age group. The mean BMI of JP men (age about 33 years) was 24.5 (95\% CI $24.2,24.8) \mathrm{kg} / \mathrm{m}^{2}$. The BMI means of the NHANES II women $^{(13)}$ for 20-29 and 30-39 years age groups were 23.1 and $24.9 \mathrm{~kg} / \mathrm{m}^{2}$, respectively. The mean BMI of the JP women was much lower $\left(21 \cdot 1(95 \%\right.$ CI $\left.20 \cdot 8,21 \cdot 3) \mathrm{kg} / \mathrm{m}^{2}\right)$. This difference supports the conclusion that the JP women were leaner than the general American population. A comparison of the TIGER men and women with Centers for Disease Control and Prevention (CDC) anthropometric reference data obtained in the years $1999-2002^{(14)}$ suggested that the body composition of the TIGER samples were representative of American adults. The BMI of the TIGER men $(27.3$ (95\% CI $26 \cdot 8,27.9) \mathrm{kg} / \mathrm{m}^{2}$ ) was within chance variation of the mean BMI of $27.0 \mathrm{~kg} / \mathrm{m}^{2}$ for the 1999-2002 NHANES American men aged 20-29 years. The mean BMI for the 1999-2002 NHANES women was $26.8 \mathrm{~kg} / \mathrm{m}^{2}$, within chance variation of the TIGER mean of $26.4(95 \% \mathrm{CI}$ $25.9,26.9) \mathrm{kg} / \mathrm{m}^{2}$. The TIGER data exhibited the same race/ethnic group trends as the $\mathrm{CDC}$ anthropometric reference data $^{(14)}$. The mean BMI difference among TIGER men differed by less than $0 \cdot 1 \mathrm{~kg} / \mathrm{m}^{2}$ while the BMI of Hispanic and African-American women was higher than white women. The NHANES data support the assumption that the TIGER men and women were representative of contemporary Americans and that the generalised equations were developed on men who were representative of the US population at the time that the generalised equations were developed, but on women who were leaner than the general population.

The GLM analyses (Table 3) confirmed that race/ethnic group was a source of prediction bias independent of BF\%GEN. With BF\%-GEN statistically controlled, the BF\%-DXA of Hispanic women was systematically underestimated by $2 \cdot 22$

Table 4. Generalised equations and calibration equations for estimating body fat percentage from dual-energy $\mathrm{X}$-ray absorptiometry (BF\%-DXA) for race/ethnic groups of young men and women

\begin{tabular}{|c|c|c|c|}
\hline & & $R$ & SEE \\
\hline \multicolumn{4}{|c|}{ Jackson-Pollock two-component Siri equations } \\
\hline \multicolumn{4}{|c|}{ Group } \\
\hline Females & BF\%-GEN $\left(0.4453 \times \sum F\right)-\left(0.0010 \times \sum \mathrm{F}^{2}\right)-0.5529$ & 0.84 & 3.9 \\
\hline Males & BF\%-GEN $\left(0.3460 \times \sum M\right)-\left(0.0006 \times \sum \mathrm{M}^{2}\right)-3.9428$ & 0.91 & $3 \cdot 4$ \\
\hline \multicolumn{4}{|l|}{ DXA equations } \\
\hline White & $B F \%-D X A=\left(0.4446 \times \sum F\right)-\left(0.0012 \times \sum F^{2}\right)+4.3387$ & 0.86 & $3 \cdot 8$ \\
\hline Hispanic & $\mathrm{BF} \%-\mathrm{DXA}=\left(0.4446 \times \sum \mathrm{M}\right)-\left(0.0012 \times \sum \mathrm{F}^{2}\right)+6.7066$ & 0.83 & $3 \cdot 4$ \\
\hline Males & & & \\
\hline White & $B F \%-D X A=\left(0.2568 \times \sum F\right)-\left(0.0004 \times \sum F^{2}\right)+4.8647$ & 0.92 & $3 \cdot 0$ \\
\hline Hispanic & $B F \%-D X A=(0.2568 \times \bar{\Sigma} F)-\left(0.0004 \times \bar{\Sigma} F^{2}\right)+5.5458$ & 0.91 & 3.0 \\
\hline African-American & $\mathrm{BF} \%-\mathrm{DXA}=\left(0.2568 \times \sum \mathrm{F}\right)-\left(0.0004 \times \sum \mathrm{F}^{2}\right)+3.8954$ & 0.95 & $2 \cdot 6$ \\
\hline
\end{tabular}

SEE, Standard error of the estimate; BF\%-GEN, body fat percentage from Siri's two-component percentage fat equation; $\sum F$, sum of triceps, supra-ilium and thigh skinfolds; $\sum M$, sum of chest, abdomen and thigh skinfolds. 
(95\% CI 1.50, 2.95) \% compared with white and AfricanAmerican women. Compared with white men, the BF\%-GEN prediction bias was $0.73(95 \%$ CI $0.07,1.39) \%$ for Hispanic men and -0.81 (95\% CI $-1.52,-0.11) \%$ for African-American men. Several investigators ${ }^{(26-31)}$ have reported that $\mathrm{BF} \%$ estimated with $\mathrm{BMI}$ regression equations developed using data from white men and women yielded biased estimates for non-white race groups. This bias has been attributed to variation in bone mineral content ${ }^{(32)}$ and body build $^{(28,33-35)}$. We examined the likelihood that bone mineral content was a source of the bias with these TIGER subjects. Bone mineral content, expressed as the percentage of total DXA weight, was added as an independent variable. Adding bone mineral content altered the men's GLM results presented in Table 3. The African-American effect for men was no longer statistically significant $(P=0.749)$, but the effect for Hispanic men remained. Adding bone mineral content to the women's GLM did not influence the women's results. These post hoc GLM analyses suggested that bone mineral content variation was a source of bias for African-American men, but not Hispanic men or women. Race/ethnic group bias has been documented $^{(26-31)}$ relating BMI to $\mathrm{BF} \%$, but this is the first study, to our knowledge, that documented a race/ethnic group bias with skinfold prediction equations.

While the sample differences in body composition shown in Table 1 were a likely source of prediction bias, the use of different referent, BF\% criteria was another potential source of bias. The criterion for the JP generalised equations ${ }^{(10,11)}$ was hydrostatically measured body density ${ }^{(15)}$ converted to $\mathrm{BF} \%$ with the Siri $2-\mathrm{C}$ model $^{(16)}$. The referent criterion for the TIGER subjects was BF\%-DXA, a multicomponent model $^{(18)}$. A search of the literature found twenty-three sets of data ${ }^{(36-45)}$ with published means for BF\%-DXA and either body density or Siri 2-C BF\%. Hydrostatic weighing was used to measure body density for eighteen of the paired datasets and air-displacement plethysmography was used for the remaining five. The sample sizes ranged from ten to 160 subjects and the mean ages ranged from 21 to 49 years. To control for variation in sample size, each mean was multiplied by its sample size (mean $\times n=\Sigma \mathrm{X}$ ). The calculated $\Sigma \mathrm{X}$ values for each dataset were summed and used to compute the mean for all 1177 subjects and for men and women. The mean difference between DXA and Siri 2-C BF\% for all men and women was small, just $0.04 \%$. When compared by sex, the grand mean of the 473 females was $1.86 \%$, compared with $-0.72 \%$ for the 704 men. This showed that the Siri 2-C $\mathrm{BF} \%$ tended to underestimate BF\%-DXA of women, which is consistent with the present results.

Other investigators have reported that the generalised equations underestimated multicomponent $\mathrm{BF} \%$ measurements. Clasey et al. ${ }^{(37)}$ reported that the generalised equations underestimated four-compartment BF\% by $5.9 \%$ with seventysix young and older men and women. When examined by age and sex groups, the differences ranged from $2.4 \%$ for young women to $7.9 \%$ for older women. Peterson et al. ${ }^{(46)}$ reported that the JP women's equation underestimated the four-compartment $\mathrm{BF} \%$ of ninety-one women by $6.6 \%$. Ball et al. ${ }^{(47)}$ reported that the generalised equation underestimated BF\%-DXA by slightly more than $3 \%$ in 160 men who ranged in age from 18 to 62 years. The results of these studies showed that the JP generalised equations underestimated multicomponent BF\% of contemporary adults, which is consistent with our findings.

These findings suggest that the inaccuracy of the generalised equations may also be due to using different BF\% referent criteria. To examine this closer, the TIGER data using just white men and women were combined with the JP data. GLM evaluated the relationship between sum of skinfold fat and measured $\mathrm{BF} \%$, controlling for sex and age. The GLM dependent variable was the $\mathrm{BF} \%$ referent criterion (Siri 2-C BF\% or $\mathrm{BF} \%$-DXA) and the independent variables were the linear and quadratic sum of skinfolds, and sample (JP and TIGER). Age was included as a covariate and sample as a categorical variable. The GLM fit statistics for the combined JP and TIGER white data were $R 0.91$, SEE $3.3 \%$ for men and $R$ 0.87 , SEE $3.9 \%$ for women. The analysis of the women's data showed that the sample $\times$ skinfold fat interaction was not statistically significant $\left(F_{(2,506)}=1.18 ; P=0.279\right)$, but sample effect was significant $\left(F_{(1,506)}=20.71 ; P>0.001\right)$. An examination of the trends showed that, with age controlled, BF\%-DXA of white women was $2.86 \%$ higher than Siri 2-C $\mathrm{BF} \%$ for the same sum of triceps, supra-ilium and thigh skinfolds. In contrast, the men's sample $\times$ skinfold interaction was statistically significant $\left(F_{(1,580)}=25 \cdot 30 ; \quad P<0.001\right)$. Examining the men's GLM results showed that, with age controlled, the sum of chest, abdomen and thigh skinfolds of $90 \mathrm{~mm}$ estimated both Siri 2-C BF\% and BF\%-DXA at $25 \%$. For a sum of skinfolds $<90 \mathrm{~mm}$, the Siri $2-\mathrm{C} \mathrm{BF \%}$ estimates were lower than BF\%-DXA estimates. Estimated Siri 2-C BF\% values of 10,15 and $20 \%$ represented $\mathrm{BF} \%$ DXA values of $13 \cdot 1,17 \cdot 3$ and $21.7 \%$. The analysis of the JP sample with the white TIGER men and women also showed that the bias was a function of sex. The generalised equations underestimated the BF\%-DXA of both men and women, but the prediction bias of the generalised equations was consistent over all BF\% levels of women and below about $25 \%$ for men. This trend was also shown with the Bland-Altman analyses provided in Fig. 2. These data suggested that the sources of inaccuracy of the generalised equations were not just due to JP and TIGER sample differences, but also different BF\% referent criteria. The equations in Table 4 provide an accurate calibration method of BF\%-DXA for white, Hispanic and African-American young men and women.

The results of the present study showed that the JP generalised equations were highly correlated with BF\%-DXA, but lacked accuracy, the generalised equations systematically underestimating BF\%-DXA. The GLM analysis documented that race/ethnic group was an independent source of the prediction bias. Compared with white men and women, the generalised equations systematically underestimated the BF\%-DXA of Hispanic men and women, and overestimated the BF\%-DXA of African-American men. Public health data document that the American population is becoming more obese and diverse ${ }^{(13,14)}$. The results of the present study demonstrate that the generalised equations need to be re-examined and updated as the body composition characteristics of populations evolve. The calibration equations provide a valid and accurate statistical model to estimate the BF\%-DXA of white, Hispanic and African-American men and women, aged 17-35 years. Further calibration research is needed with older men and women. 


\section{Acknowledgements}

Support for the present study was provided by the National Institute of Diabetes and Digestive and Kidney Diseases/ National Institutes of Health grant R01-DK062148 and by US Department of Agriculture/Agricultural Research Service (USDA/ARS) contract 6250-51000-046. A. S. J. designed the study, conducted the data analyses and prepared the manuscript. K. J. E. and B. K. M. were responsible for the DXA measurements and reviewed and edited the submitted manuscript. M. H. S. was responsible for database management and aided in the data analyses. M. S. B. aided in the design, data analyses and writing the manuscript. The authors have no professional relationships with companies or manufacturers who might benefit from the results of the present study.

\section{References}

1. Bellisari A \& Roche AF (2005) Anthropometry and ultrasound. In Human Body Composition, chapter 8, pp. 109-127 [SB Heymsfield, TG Lohman, Z Wang and SB Going, editors]. Champaign, IL: Human Kinetics.

2. Sun SS \& Chumlea WC (2005) Statistical methods. In Human Body Composition, chapter 11, pp. 151-160 [SB Heymsfield, TG Lohman, Z Wang and SB Going, editors]. Champaign, IL: Human Kinetics.

3. Katch FI \& Michael ED (1968) Prediction of body density from skinfold and girth measurements of college females. J Appl Physiol 25, 92-94.

4. Katch FI \& McArdle WD (1973) Prediction of body density from simple anthropometric measurements in college age women and men. Hum Biol 45, 445-454.

5. Sloan AW, Burt JJ \& Blyth CS (1962) Estimation of body fat in young women. J Appl Physiol 17, 967-970.

6. Sloan AW (1967) Estimation of body fat in young men. J Appl Physiol 23, 311-315.

7. Pollock ML, Laughridge E, Coleman B, Linnerud A \& Jackson AS (1975) Prediction of body density in young and middle-aged women. J Appl Physiol 38, 745-749.

8. Pollock ML, Hickman T, Jackson AS, Kendrick Z \& Dawson G (1976) Prediction of body density in young and middle-aged men. J Appl Physiol 40, 300-304.

9. Durnin JVGA \& Wormsley J (1974) Body fat assessed from total body density and its estimation from skinfold thickness: measurements on 481 men and women aged from 16 to 72 years. Br J Nutr 32, 77-92.

10. Jackson AS \& Pollock ML (1978) Generalized equations for predicting body density of men. Br J Nutr 40, 497-504.

11. Jackson AS, Pollock ML \& Ward A (1980) Generalized equations for predicting body density of women. Med Sci Sport Exerc 12, 175-182.

12. Trayhurn P (2004) BJN 'Citation Classic'. Br J Nutr 91, $160-168$.

13. Flegal KM \& Troiano RP (2000) Changes in the distribution of body mass index of adults and children in the US Population. Int J Obes 24, 807-818.

14. McDowell MA, Fryar CD, Hirsch R \& Ogden CL (2005) Advance Data: Anthropometric Reference Data for Children and Adults: U.S. Population, 1999-2002, pp. 1-32. US Department of Health and Human Services, Centers for Disease Control and Prevention, National Center for Health Statistics. http:// www.cdc.gov/nchs/data/ad/ad361.pdf

15. Going SB (2005) Densitometry. In Human Body Composition, chapter 2, pp. 17-34 [SB Heymsfield, TG Lohman, Z Wang and SB Going, editors]. Champaign, IL: Human Kinetics.
16. Siri WE (1961) Body composition from fluid space and density. In Techniques for Measuring Body Composition, pp. 223-244 [J Brozek and A Hanschel, editors]. Washington, DC: National Academy of Science.

17. Lohman TG, Harris M, Teixeira PJ \& Weiss L (2000) Assessing body composition and changes in body composition - another look at dual-energy X-ray absorptiometry. Ann N Y Acad Sci 904, 45-54.

18. Lohman TG \& Chen Z (2005) Dual energy X-ray absorptiometry. In Human Body Composition, chapter 4, pp. 63-78 [SB Heymsfield, TG Lohman, Z Wang and SB Going, editors]. Champaign, IL: Human Kinetics.

19. Wang Z, Shen W, Withers RT \& Heymsfield SB (2005) Multicomponent molecular level models of body composition analysis. In Human Body Composition, chapter 12, pp. 163-176 [SB Heymsfield, TG Lohman, Z Wang and SB Going, editors]. Champaign, IL: Human Kinetics.

20. Baumgartner TA, Jackson AS, Mahar MT \& Rowe DA (2007) Measurement for Evaluation in Physical Education and Exercise Science, 8th ed. New York: McGraw-Hill.

21. Jackson AS \& Pollock ML (1985) A practical approach for assessing body composition of men, women, and athletes. Physician Sportsmed 13, 195-206.

22. StataCorp (2007) User's Guide: Release 10. College Station, TX: StataCorp LP.

23. Pedhauzur EJ (1997) Multiple Regression in Behavioral Research: Explanation and Prediction, 3rd ed. New York: Harcourt Brace College Publishers.

24. Altman DG \& Bland JM (1983) Measurement in medicine: the analysis of method comparison studies. Statistician 32, 307-317.

25. Altman DG \& Bland JM (1986) Statistical methods for assessing agreement between two methods of clinical measurement. Lancet i, 307-310.

26. Chang CJ, Wu CH, Chang CS, Yao WJ, Yang YC, Wu JS \& Lu FH (2003) Low body mass index but high percent body fat in Taiwanese subjects: implications of obesity cutoffs. Int $J$ Obes 27, 253-259.

27. Chung S, Song J, Shin H, Kim D, He Q, Heshka S, Wang J, Thornton J, Laferrere B, Pi-Sunyer FX \& Gallagher D (2005) Korean and Caucasian overweight premenopausal women have different relationship of body mass index to percent body fat with age. J Appl Physiol 99, 103-107.

28. Deurenberg P, Yap M \& van Staveren WA (1998) Body mass index and percent body fat: a meta analysis among different ethnic groups. Int J Obes 22, 1164-1171.

29. Deurenberg-Yap M, Schmidt G, van Staveren WA \& Deurenberg P (2000) The paradox of low body mass index and high body fat percentage among Chinese. Malays and Indians in Singapore. Int J Obes 24, 1011-1017.

30. Fernández JR, Heo M, Heymsfield SB, Pierson RN Jr, Pi-Sunyer FX, Wang ZM, Wang J, Hayes M, Allison DB \& Gallagher D (2003) Is percentage body fat differentially related to body mass index in Hispanic Americans. African Americans, and European Americans? Am J Clin Nutr 77, 71-75.

31. Jackson AS, Stanforth PR, Gagnon J, Rankinen T, Leon AS, Rao DC, Skinner JS, Bouchard C \& Wilmore JH (2002) The effect of sex, age, and race on estimating percent body fat from BMI: the HERITAGE Family Study. Int J Obes 26, $789-796$

32. Wagner DR \& Heyward VH (2000) Measures of body composition in blacks and whites: a comparative review. Am J Clin Nutr 71, 1392-1402.

33. Deurenberg P, Deurenberg-Yap M, Wang J, Lin FP \& Schmidt G (1999) The impact of body build on the relationship between body mass index and body fat percent. Int J Obes $\mathbf{2 3}$, 537-542. 
34. Deurenberg P, Deurenberg-Yap M, Wang J, Lin F \& Schmidt G (1999) The impact of body build on the relationship between body mass index and body percent fat. Int J Obes 23, 537-542.

35. Guricci S, Hartriyanti Y, Hautvast J \& Deurenberg P (1999) Difference in the relationship between body fat and body mass index between two different Indonesian ethnic groups: the effect of body build. Eur J Clin Nutr 53, 468-472.

36. Ball SD \& Altena TS (2004) Comparison of the Bod Pod and dual energy X-ray absorptiometry in men. Physiol Meas 25, 671-678.

37. Clasey JL, Kanaley JA, Wideman L, Heymsfield SB, Teates CD, Gutgesell ME, Thorner MO, Hartman ML \& Weltman A (1999) Validity of methods of body composition assessment in young and older men and women. J Appl Physiol 86, 1728-1738.

38. Minderico CS, Silva AM, Teixeira PJ, Sardinha LB, Hull HR \& Fields DA (2006) Validity of air-displacement plethysmography in the assessment of body composition changes in a 16-month weight loss program. Nutr Metab 3, 1-8.

39. Prior BM, Cureton KJ, Modlesky CM, Evans EM, Sloniger MA, Saunders M \& Lewis RD (1997) In vivo validation of whole body composition estimates from dual energy X-ray absorptiometry. J Appl Physiol 83, 623-630.

40. Sardinha LB, Lohman TG, Teixeira PJ, Guedes DP \& Going SB (1998) Comparison of air displacement plethysmography with dual-energy X-ray absorptiometry and 3 field methods for estimating body composition in middle-aged men. Am $J$ Clin Nutr 68, 786-793.

41. Snead DB, Birge SJ \& Kohrt WM (1993) Age-related differences in body composition by hydrodensitometry and dualenergy X-ray absorptiometry. J Appl Physiol 63, 770-775.

42. Van der Ploeg GE, Withers RT \& Laforgia J (2003) Percent body fat via DEXA: comparison with a four-compartment model. J Appl Physiol 94, 499-506.

43. Wellens RI, Roche AF, Khamis HJ, Jackson AS, Pollock ML \& Siervogel RM (1996) Relationships between body mass index and body composition. Obes Res 4, 35-44.

44. Weyers AM, Mazzetti SA, Love DM, Gomez AL, Kraemer WJ \& Volek JS (2002) Comparison of methods for assessing body composition changes during weight loss. Med Sci Sport Exerc 34, 497-502.

45. Withers RT, LaForgia J, Pillans RK, Shipp NJ, Chatterton BE, Schultz CG \& Leaney F (1998) Comparison of two-, three-, and four-compartment models of body composition analysis in men and women. J Appl Physiol 85, 238-245.

46. Peterson MJ, Czerwinski SA \& Siervogel RM (2003) Development and validation of skinfold-thickness prediction equations with a 4-compartment model. Am J Clin Nutr 77, 1186-1191.

47. Ball SD, Altena TS \& Swan PD (2004) Comparison of anthropometry to DXA: a new prediction equation for men. Eur J Clin Nutr 58, 1525-1531. 